\title{
Medical Themes and Metaphors in Urhobo Oral Song-Poetry
}

\author{
Peter Emuejevoke Omoko \\ Department of English, University of Africa, Toru-Orua, Nigeria
}

Email address:

peteoms@gmail.com, peter.omoko@uat.edu.ng

\section{To cite this article:}

Peter Emuejevoke Omoko. Medical Themes and Metaphors in Urhobo Oral Song-Poetry. International Journal of Literature and Arts. Vol. 9, No. 4, 2021, pp. 161-167. doi: 10.11648/j.ijla.20210904.13

Received: June 9, 2021; Accepted: June 26, 2021; Published: July 22, 2021

\begin{abstract}
The discourse on the therapeutic function of literature has, in recent years, been given critical attention in Nigeria. However, little interest has been paid to the representation of illnesses and healing in the field of African oral literature. Oral texts like songs, folktales, myth and incantation, foreground physical and mental conditions. In such autochthonous societies, the totality of the people's belief about different ailments, social disorders, death, life and the afterlife, constitute the entire gamut of the ingredients of their oral and artistic productions. They represent an essential aspect of the people's indigenous knowledge system handed down from generation to generation. This is because the African people express the depth of their feelings and emotions in their oral composition and cultural practices. The aim is to help younger generation to be conscious of their mental health and spiritual wellbeing. This work is therefore motivated by the need to interrogate the nexus between oral poetry and medicalisation, which falls within the domain of the medical humanities. It undertakes a close investigation of the diverse spheres of metaphorical representations, allusions and themes inherent in selected oral texts in connection with Psychiatry, ill-health and well-being in Urhobo oral song-poetry. The work relies on the sociological approach to literature that emphasizes the extrinsic relationship between art and society to determine the formal structure, themes, and images of illhealth, disease, pathological disorders and wellness that have endeared the people to their environment for many decades. The work argues that the mental health of the individual relates significantly to the overall wellbeing of the society; it engenders the maintenance of the cosmic order, the relationship between the individual and other segments of the psychic environment - the physical and spiritual.
\end{abstract}

Keywords: Urhobo, Song-poetry, Medical Humanities, Psychiatry, Ill-health and Wellbeing

\section{Introduction}

The nexus between Literature and medicine has received much critical attention in recent years. Scholars have interrogated various aspects of the twin-domains and have established that there is a lot to benefit mankind if literature is given significant vent in clinical studies. This is because the artist's work, it is believed, "despite satisfying the entertainment needs of the audience, must be 'functional', beneficial in such a way that proffers solutions to society's many problems" [1]. On this note, Kekeghe submits: "The depictions of mental illnesses, in Nigerian literature, underscore the social commitment of the modern African writer, whose socialist vision is to reflect and refract societal experiences" [2]. Faith Mclellan agrees with the above views when she affirms that "works of art which encapsulate medical themes, help the reader to reflect deeply about life, especially the transience of life and the mortality of man" [3].

\section{Literature Review}

In his study of the importance of the humanities to medicine, I. E. Mcmanus believes that the medical profession will be better if clinicians embrace the humanity inherent in the work of arts. According to him, "having knowledge of the arts, especially literature, could enhance the competence of the physician. He also argues that, for medicine to have a human face and medical doctors to become more relevant to the society, doctors would have to recognise the significance of the humanities to the full understanding of man and society". Mcnanus' thesis is centred on the premise that "the humanities symbolise a mirror through which the medical 
doctor can see his own reflections or the reflections of other people". Other scholars who have done close study of literary texts and medicine have also expressed similar sentiments about the usefulness of literature to clinical studies. Allan Beveridge tells us that creative "books about illness and suffering help doctors to better understand the inner experience of their patients and, as a consequence, to develop greater empathy" [4].

Omobowale, one of the pioneer scholars in the field of literature and medicine in Nigeria, confirms that "...different works of art where characters have been depicted falling sick or being afflicted with disease, the role of the doctors or physician as healers often come under the close scrutiny of many readers because of the doctor's position as an important pillar of society" [5]. He therefore assures that since "literature is a reflection of life and human medicine guarantees physiological and psycho-social equilibrium, [he has] no doubt that literature and medicine, not only complement each other, they also aim at similar objectivesalbeit using different methods".

Femi Oyebode, on his part, examines the usefulness of poetry in clinical studies and believes that "the aspect of poetry that is to do with the expression of passion and emotions, draws out why poetry can be so important in the psychiatric context" [6]. Here, Oyebode bases his submission on the notion of "passion and emotion" which constitute the basic tenets of great poetry. Both T. S. Eliot and Edgar Allan Poe have had course to relate poetry to powerful emotional feelings [7]. Hence Oyebode tells us further that poetry is "often able to speak directly and cogently, to get to the heart of a subject in a few choice words, to draw us into the spirit of the moment, to engage our attention and empathy, and ultimately render visible the humanity in particular experiences" [8]. With these efforts made to associate the studies of literature to medicine, therefore, it is necessary to explore the role of oral literature, a domain from which much of modern African literature derives, to medical humanities. Modern African literature is a broader corpus of African oral literature. Thus there is the need to examine the usefulness of oral literature on the evolving field of literature and medicine. Since it has been established that there is significant connection between literature and medicine, it is also pertinent to explore the role of African oral literature in the area of illness and wellness.

If it is true that all literatures derive from serious mental engagement, deep thoughts and profound attitude in an imaginative atmosphere to recreate human experiences; oral literature is not out of such axiomatic assertion. Oral literature underscores the totality of the people's artistic creation, either in the form of songs, narratives or dramatic enactments. Its influences on the social and religious life of the people is often foregrounded in their myths which reveal why and the wherefore of creation, an idea that regulates the socio-religious consciousness of the people as well as their folktales which are the age-long instrument for bringing up children under the ethical standard of the society. In fact, in traditional African societies, the balance between the human and supernatural world is jealously guarded. This is because, it defines the degree of societal wholeness or otherwise. Thus when studied against contemporary clinical studies, oral literature has the potentials to open more frontiers to the usefulness of literature to medical studies. The structural patterns, the diversity of themes, the images, metaphorical allusions, and the performance strategies in many oral texts demonstrate that the medical science has a lot to benefit from the resources of oral literature. The point being made here, however, is not to seek a side-by-side application of clinical methodology and literary insights into the treatment of emotional or mental ailment, nor a replacement of the scientific modes in medical science with literary analysis; however, it is hoped that the understanding of literary endeavours as well as its role in shaping the human person will be illuminating in finding permanent remedy to many causal-effect of psychopathic conditions and other ailment in the society. To use the words of Wole Soyinka, our "interest is simply to relate the science of healing to the holism of faith, of which a most potent aspect is the word, the lyricism and poetry of healing which acts both therapeutically and homeopathically" [9].

Result

Many of the cultural productions in the form of songs and narratives in African traditional societies foreground themes and metaphors of ill-health, disease, pathological disorders and wellness. Thus, because of the close family and community ties that exist among many African societies, and the functionality of their arts, there is the tendency to recreate the totality of the people's way of life in their oral artistic creations. In the Urhobo society, for instance, we find in many of the oral song-poetry images of mental disorder, diseases and deaths recreated in a manner that will benefit clinicians, especially with regards to traditional African medicine. Kekeghe's [10] pathotextual reading of Urhobo folktales highlights the African indigenous philosophy of health management in oral narratives. In the study, Kekeghe attempts to formulate a patho-textual theory that intersects the literary and medical fields. He illustrates further:

The term, 'patho', is an offshoot of a Greek word, 'pathos', which denotes suffering or disease. In other words, 'patho' or 'pathy' simply indicates illness or disease while pathology is the scientific study of the nature, causes and manifestations of diseases. 'Text', on the other hand, indicates creative or literary works. 'Pathotext', therefore, suggests literary texts that explore illnesses and diseases.

In traditional oral societies, it is believed that sustained emotional distress could cause depression and death - hence they evolve various cultural practices that engage the people in art and entertainment. Annual festivals, song contests, folktale telling sessions, and other artistic practices are all geared towards promoting wellness among the people. The people believe that emotional challenge, if not properly managed can constitute danger to everyone else in the society. It is against this backdrop that David Okpako suggests to all clinicians that "emotional distress must be noted as an illness risk factor of particular significance in the sub-Saharan 
African environment. However, there is also the believe in many oral cultures that some mental disorders or serious illness could result from spiritual means or one's personal wrong doing against the spiritual equilibrium of the society, in what Okpako would call "ancestor spirit anger". In any of these instances, the mode of treatment must draw from the spiritual mechanism of the society. Among the Urhobo people of Nigeria, serious illness that could not be cured by the regular clinical ministration is often referred to the medicine man who uses various ritual/metaphysical mediums to decipher the cause of the ailment before treatment is administered. If it is diagnosed that the person has committed a serious immoral act against a neighbour or descendant (emuerivwin) for which only the ancestors can adjudicate, the individual is made to confess his/her sins openly before any medicine applied on him/her can be effective. Okpako notes that: "in traditional African medicine the basic principle around which all practices hover, is the knowledge from experience that serious illness can have its roots in the mind, in sustained emotional distress". According to him, it is this "idea that is crystallised as ancestor spirit anger belief" [11]. This submission is a significant entry point for clinicians into the understanding of the medical nuances required in the diagnosis and treatment of emotional disorder and serious ailments in rural societies. As shall be shown shortly from the selected texts in this essay, the people are not unaware of the place of the supernatural in the affairs of man that in the event of apparent disruption in the spiritual equilibrium between the sick person and the ancestors, he/she must accepts willingly his/her ultimate fate in the event that clinical efforts fail.

\section{Method}

The analytical method is adopted in this essay to bring out the salient themes and medical metaphors in the selected oral songs-poems. The primary sources for the study are obtained from recorded audio cassette tapes and compact discs of the musicians. The selection of texts is taken from the corpus of the musical duet, Sir Juju Debala and Udjabor Okololo of Urhobo.

The choice of the song-poems was made because they best exemplify the qualities of complexity of medical themes and metaphors which constitute the focus of this essay. The representative song-poems are transcribed and translated from the original language (Urhobo) into the target language (English).

Correspondingly, analysis of the transcribed texts is attempted to bring out the salient features of medicalisation and cultural nuances in them. This approach enabled us to establish the place of oral literature in clinical studies. The data gathered from the sources above are supplemented with published materials in books and journals that are relevant to oral literature, in general, and clinical studies, in particular.

\section{Discussions-Themes and Metaphors of Illness in Urhobo Song-Poetry}

Every literature tells a story. Poetry, however short and compact it might be, tells as much story as novels and plays. In traditional African societies, art, certainly, is functional. It is created in response to certain cultural value and moral code that distinguish the people from others. In the Urhobo society, for instance, songs are composed in response to specific happenings, changing cultural orientations as well as psychosocial situations. The aim, one may argue, is to place society on a constant moral and ethical check. Also, in traditional oral societies, many of the significant values of the community - history, myths and legends, are codified in their songs. Hence, we believe that physicians will benefit more from the different metaphorical motifs that are salient in the oral poetry and narratives of the African people than we can find in other materials. The importance of oral literature to the African people as well as its functional uses in the aesthetics of modern African literature and clinical studies is well illustrated by Igboanusi when he avers that:

the oral tradition is very important to Africans in general because their behaviours, thoughts, language and rhetoric are moulded and shaped by their tradition. Similarly, their creative imagination, history, medicine, technology and philosophy were orally passed down to different generations through various forms of oral performance [12].

In the remaining part of this essay, we shall demonstrate how oral poetry describes various experiences of mental disorder, communal sorrow, diabolic manipulations, psychosocial crises and death. In this respect, the vulnerability of the victims as well as the society's actions and inactions constitute the overall aesthetic flavour of the songs. Two song-poems from the corpus of the Sir Juju/Udjabor group of Urhobo would be examined to illustrate the above position.

In the song "Bidofor" the artists describe the mental anguish of a young man which climaxed in the gruesome murder of his own mother. The song tells of a young man, Avwọnkuruo who gets enlisted into the Nigerian police force but finds himself entangled in a family underlying squabble that results in him being attack, through diabolic means with mental illness. The victim, after his first promotion, is invited to come home by his uncle, Asifọ for fortification. When he gets home, his uncle gives him two concussions, one to make him bold and fearless in the course of his duty, the other, a wand to dispel all evil plots directed at him. Avwonkuruo collects the charms and goes back to Lagos, not knowing that he has been poisoned through diabolic means with spiritual psychosis.

Sifọ invited him for advice

"As my sister's son be attentive

No one goes to the police force without fortification

The fortification you'll need I've procured them!

This pouch is for bravery

This small clay pot is for anti-dote

Little did he know that it was meant for his destruction

After taking the charms, Avwọnkuruo becomes 
psychoactive. His mind is affected by the charms and he begins to manifest different depressive episodes. First, he could not recognise his environment or his way to his office in Lagos. He asks neighbours to show him his office but they look at him as one who is insane. As his condition worsen, he thought within himself that it would be better if he seeks cure from home. He thus returns home to seek help from the very man who puts him in his psychiatric condition. He meets his uncle and pleads with him to remove his evil spell from his body. But the uncle refuses and swore never to cure him from his mental illness. In anger, he goes to his house and burnt it down. In the village, his mental state deteriorated. He becomes emotionally depressed. People laugh and sneer at him as he patrols the town aimlessly.

With his police uniform he returns home in a hurry

And started perambulating about town

Like a ship adrift on a dry land

The swallow bird never gets lost in a foreign land

It is an impossibility!

He used to soliloquise:

"Whether this is Lagos I can't even tell

Somebody should show me the way to my office"

He appeals to Asifo to take back his charms

Asifo said, "never, never will I free you from the spell"

From the above lines, the keen listener will surely empathise with Avwọuruo whose jealous uncle has diabolically made to go mad. His restlessness and the mounting sense of insecurity that made him to abscond from his police duties in Lagos to the village not only sends a measure of embarrassment to the listeners who have identified with his progress in the police force, but create a kind of alluring suspense of what his next action would be. Besides, the attitude of the uncle should be of interest to physicians with respect to the treatment of psychiatric condition in Africa. This is because, many of the ailments, especially when the victim is a young person, are believed to be caused by either a jealous relative or an immoral sin committed by the victim against the 'ancestor spirits' of the family. In this case, it is the former that suffices. But to what end? The obvious suggestion would be that the uncle was jealous that it is from his young sister's blood line that someone would prosper to elevate the family. Hence he refuses to free the victim from his psychopathic spell.

Thus, on a particular day, Avwọnkuruo refuses to accept his dementia condition; he goes to the market and buys a machete. He sharps its blade thoroughly - after smoking marijuana, he goes to his mother and demands instant cure for his mental ailment. The innocent mother pleads that she does not know where Asifọ, her brother gets the diabolic charm that is tormenting him from. Despite the mother's plea, Avwọkuruo hacks her to death.

Alas! In the dead of the night

The spell overcame him

He went and knocked at his mother's door,

"Open so that I can light up my lamp,

My lamp has gone off and the lighter doesn't have stones"

Her mother's body had given her a signal:
She answered that her lamp had also gone off

And there were no matches in the house

The mother peeped through the window

And saw a baton in his hand and a machete,

Smoking a cigarette

Hey, hey! The famous marijuana!

Avwonkuruo finished smoking marijuana

And told himself, "there is nothing to live for"

He broke down his mother's door

Saying: "today we shall end it all"

He engaged his mother in a duel

Like Indian characters in a film

The mother ran into the room and hid herself

She couldn't endure it, she ran out

And there she was hit at the neck with a club

As she was being slaughtered, she pleaded:

'My child, please take pity

I don't know where Sifọ got his charms from

'You are killing me unjustly, let me go'

Alas! Death by a cutlass is gruesome!

As mother's blood spilled

Tẹn tẹn rẹn tẹn rẹn rẹn!

How he butchered the mother like an animal

Her heart he put aside

Her kidney he reserved for use

Parts of her head he threw to dogs for a feast

Oh, tragedy, tragedy, tragedy!

The above lines will certainly either make the attentive listener to go numb or shed tears on the horror that accompanies the death of Bidọfọ - an innocent mother who had nothing to do with her only child's dementia travails. Besides, the fear that grips the mother the moment the son comes to request for a lighter to light his cigarette will frighten the listeners. Here, the mother's assessment of the son's mental state is that of grief and fear. Hence the poets intone in the song that:

The mother ran into the room and hid herself

She couldn't endure it, she ran out

And there she was hit at the neck with a club

The child's condition must have pained the mother that in her emotional state utter some words of regrets. This is why Allan Beveridge believes that in "contrast to the more detached position of the psychiatrist assessing a patient, we are plunged into the everyday reality of life with a mentally ill relative. Furthermore, the description of the horror and violent slaughter of the mother who is cut to pieces and displayed as wares in the market only foregrounds the depth of the psychopathic state of the subject. The reader is made to share in the mother's pain when she begs for her life. The listener will not only feel the mother's pain but would shed tears in what Skelton would call "a sense of luxurious sadness" [13] as the poets increase the tempo of the song thus: Alas! Death by a cutlass is gruesome!/As mother's blood spilled/Tẹn tẹn rẹn tẹn rẹn rẹn! This abominable act of a son killing his own mother only explains the level of pathological destruction that the concussions must have had on the boy's psyche. The uncle's devilish act not only destroys the victim 
and his mother but constitutes a communal indictment to the community. To this end, the uncle, Asifọ typifies a community who destroys its own through diabolic means, a community that abhors progress and above all, a curious community that must be dreaded. This is because in Africa, mental illness is well dreaded by the people and a family that has a history of mental sickness is avoided especially when it has to do with marriage that knits family together. It is against this backdrop that Beveridge notes that, "mental illness does not take place in isolation: it affects relatives and wider society".

Besides, the sense of loss the mother suffers is heightened when at the ancestral world she is refused smooth passage to her kindred court.

Spectators join me in my song!

The death of Kopa has chilled my blood

Whenever I see a slaughter house, I recall it

When the mother got to Urhoro the gatekeeper queried her:

'Your full time has not yet come

Why did you come this early?'

The implication of the above lines is that the mother's erhi (soul) in the afterlife will be left to wander helplessly without becoming an ancestor. According to Nabofa, "those to whom the gates of urhoro are barred become wandering spirits who go about as mischievous being" [14].

A significant aspect of the song that would interest clinicians is the state of Avwokuruo the moment he sees his fellow policemen who have come to arrest him. He immediately becomes stable and realises that he has committed murder; a crime he knows too well carries a capital punishment.

News get to Warri

Police has come

Vwokuruo sees them and starts crying:

"Look at me, a police man,

Who understands the law - but kills his mother

Unjustly! Unjustly!'

Police that came to arrest him also cry

It's only cry that sends the dead to the grave

What the oral artists have done in this segment of the song is to underscore the fact that the subject's psychiatric condition is not a medical situation that could have been handled by the general clinical treatment of psychopathic condition. Rather, it is a condition that requires spiritual intervention where the uncle, Asifọ would have been forced to undo the effect of the charm on the subject. This is because the Urhobo people believe, like other African people, that a person who concocts a charm also possesses the antidote. In other words, it is not all psychopathic conditions that require the rudimental clinical intervention.

Furthermore, oral literature, like its written counterpart, is able to create in the listeners, a sense of personal consideration of moments of depressive episodes and the totality of the human life especially as it affects sickness and death. Thus many of the oral song-poetry of the Urhobo people contains significant metaphors and allusion that foreground the whole system of clinical ideas on which the people's belief about illness and death is birthed. John Skelton tells us that:

it is not always the aim of literature to present us with death in such a way as to make us feel personally bereaved: and in great literature, though a sense of bereavement may be the starting point for our own reveries about what we have seen or read, the aim is never merely the bereavement. Rather, it is the broader issue of what the death means.

In another song "Roniwe" from the corpus of the same poets for instance, the persona is a diviner (physician) who finds himself entangled with a serious ailment on a community's day of worship when no one is expected to do a severe work. Although he assures his adherents that all would be well because he has powers to visit the divinities/principalities at night to dispel the sickness, however, at dawn he was already incommunicado, and soon after, dies.

Alas! Isaac would say:

"How come an illness strikes a priest on the day of worship?"

Eyes have seen some wonders

Roniwe assured: "just be calm"

When he gets to the shrine

He would dispel the troublesome illness

Before dawn, the youth becomes incommunicado

"Before dawn, my lover and I went to the forest

To cut down planks meant to pay my brides wealth

Behold!

Death has snatched him away from me"

This song raises a gamut of philosophical puzzles about the human condition, illness, culture and metaphysical interplay with the individual and society. The aesthetic goal is to interrogate some cultural dilemmas which defy the syncretic process of metaphysical intrusion into the affairs of man. Why would the subject fall sick on a community day of rest when it is forbidden for anyone to do severe work? His attempt to assure his followers that he is able go to the spirit meeting to dispel the spirit of death turns out to be a vain boast as he becomes incommunicado by dawn. Thus oral literature has portrayed, in an aesthetic manner, different shades of illnesses, foregrounding the helplessness of man when death comes knocking. In other words, the curative principles of illness lies not in the over-reliance in the powers of the diviner/physician, but in the ethical standard of society that upholds good over evil. Since literature is a reflection of the life of a people, its understanding would facilitates or enhance the knowledge of clinicians in a great regard.

What the poets have shown in this song is that there is more to derive in the culture and environment of the people than mere empirical medical postulations. For instance, the subject could not get to his laboratory (shrine) to get empirical evidence about the cause of his illness because it was the spirit market day. Secondly, all attempts to get reprieve from the metaphysical domain (spirit cult) proves abortive because of the degree of the illness. In other words, physician should be sensitive about the philosophy, culture, art as well as the environmental constituents of the society. T. 
A. Lambo expresses this view when he affirms that:

Man's belief concerning his culture.... environment determines to a large extent the interpretation of concept of health and disease and the methods of therapy to be employed in resolving life crisis... Medicine in a broad sense can be regarded as a constituent part of social institutions since it is bound up with the whole interpretation of life [15].

The subject, being a diviner, may have over-stepped his boundaries through act of uncleanness and immorality which among the people his known as 'emuerivwin'. As a medicine man, the subject is expected to attend to his client with open mind. He must not be boastful because his powers are divine or use his powers against a family member or descendant. Should he go against these cultural principles; he is deemed to have committed a crime against the ancestors who alone have the powers to adjudicate in his case. This is why Okpako defines emuerivwin as "an immoral act for which the ancestors may punish an offending descendant with serious illness" [16]. The oral artists indicate this idea in a segment of the song thus:

Ancestors distributed letters,

It pasted letters

Whoever comes late would pay a fine

"You should go and tell my brother

To stop mourning, it is the last house that marks the end of a settlement

"I, the one who determines the day

Of worship in the shrine

Behold, the storm has fell the king of plantain

The import of the subject's confession of his inability to convince death to spare his life derives from the fact that his immoral act is an abomination against the metaphysical principalities which he represents. Therefore, since his illness is associated with personal misdemeanour against the social equilibrium of the society, personal confession is required for propitiation sacrifices. In this case, wellness is believed to come from the victim's state of mind and little of the drugs administered. It is in this regard that Okpako argues that in traditional societies, the African experience of serious illness:

is strongly linked to bad behaviour, the symptomatic treatment of serious illness includes the so-called esoteric practices (confession of sin, divination, propitiation sacrifices, incantations, etc.) that have the effect of diffusing emotional distress which, in an acculturated individual living with the consciousness of sin predisposes the victim to illness.

The subject could not get the divinities and spirit beings in the shrine to heal him of his illness because of his uncleanness. However, it is also possible that other forces greater than him may have wanted him dead. Wole Soyinka attests to this fact when he submits that "it is not merely the beneficent gods and their potencies, their curative and fortifying interventions that occupy the African pantheons, but also the combative, even malevolent, who can be invoked to work against the enemy". For example in the song, when the subject is unable to assist himself as he had boasts, he is taken to a cure-house where a medicine man is depicted as helpless to the subject's medical challenge. The poets recreated in the concluding sections of the song thus:

When the news first broke out

They took him to a cure-house

An unprecedented wailing stirred the air

And shook the foundation of the compound

A mighty tree has been uprooted

A dilemma, alas!

The mere fact that the medicine in whose cure-house the subject dies could not heal him adumbrates the indices of divine retribution. In the performance of the song the mourners are visualise as helpless as they watch the subject die in their hands.

\section{Conclusion}

The foregoing, when studied against contemporary clinical interventions, has the potentials to open more frontiers to the usefulness of oral literature to clinical studies. The diversity of themes, images, metaphorical allusions and performance strategies in the songs demonstrate that the medical science has a lot to benefit from the resources of oral literature. The discussions above further expose the fact that psychopathic conditions, ill-health and death can be induced through spiritual and diabolic mediums. However, in such instances the spiritual health of the entire community is at risk. This derives from the fact that in traditional African societies, the balance between the human and supernatural world is jealously guarded because it defines the degree of societal wholeness and otherwise. These, according to Soyinka, "are claimed potencies much derided or dismissed by the western educated mind, but it is from within such resources that, not only the religion, but the full richness of Africa's literary wealth - oral, ancient and contemporary, of the continent and the diaspora, written and rhetorical - can best be appreciated".

\section{References}

[1] Onukaogu, A. A. and Ezechi O. eds. (2009). $21^{\text {st }}$ Century Nigerian Literature: An Introductory Text. Ibadan: Kraft Books Limited, p. 22.

[2] Kekeghe Stephen Ese (2018). Psychiatric Conditions in Selected Nigerian Literary Texts, PhD Thesis, University of Ibadan, Department of English, Ibadan, p. 1.

[3] Omobowale, E. B. (2018). Healing with the Pen: Literature and the Quest to Humanise Medical Practice in Nigeria. An Inaugural Lecture. Ibadan: Ibadan University Press, p. 13.

[4] Beveridge, A. (2009). "The Benefits of Reading Literature" in Mindreading: Literature and Psychiatry. Femi. Oyebode (ed.) London: RCPsych Publications, p. 13.

[5] Omobowale, E. B. (2018). Healing with the Pen, op. cit.

[6] Oyebode, F. ed. (2009). "Poetry and Psychiatry" Mindreading: Literature and Psychiatry. London: RCPsych Publications, p. 55 . 
[7] Kermode, Frank. (1973). The Oxford Anthology of English Literature Volume II. New York: O U P, p. 1999.

[8] Oyebode, F. ed. (2009). "Poetry and Psychiatry", op. cit.

[9] Soyinka, W. (2012). Harmattan Haze on an African Spring. Ibadan: Bookcraft, p. 100.

[10] Kekeghe Stephen Ese, (2020). "Medical Episodes and Pathotextualism in Urhobo Folktales". International African conference on current studies, Ed: Srivastava, Viranjay M. Turkey: Farabi Publishing House [www.africansummit.org]. p. 434, 436.

[11] Okpako, T. D. (2019). Wellness: Urhobo Emuerivwin An African Holistic Health Ideology. Ibadan: Books Builders, p. 167.
[12] Igboanusi, p. 219, 220.

[13] Skelton, John (2009). "Death and Dying in Literature" Mindreading: Literature and Psychiatry. London: RCPsych Publications, p. 80.

[14] Nabofa, M. Y. (2011). "Erhi and Eschatology." The Urhobo People. $3^{\text {rd }}$ ed., Onigu Otite (ed.) Gold Press Limited, p. 378.

[15] Ubrurhe, J. O. (2001). Urhobo Traditional Medicine. Ibadan: Oputoru Books, p. 18.

[16] Okpako, T. D. (2014). "Speculations on the Origin of ideas in Traditional African Medicine: An Urhobo Perspective" in Aridon: The International Journal of Urhobo Studies. Number 1, p. 97. 